J. Austral. Math. Soc. 21 (Series A) (1976), 385-392.

\title{
GEORGE SZEKERES
}

\section{With affection and respect}

J. R. GILES and JENNIFER SEBERRY WALLIS

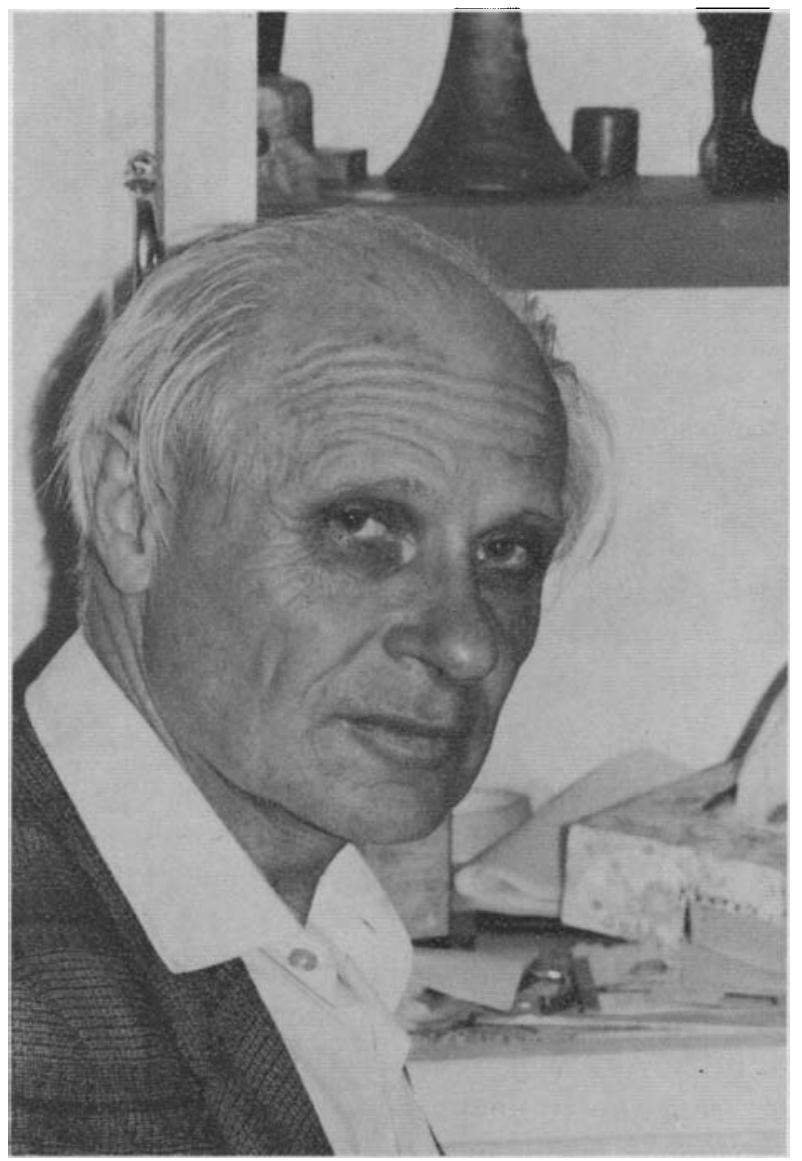

George Szekeres was born in Budapest on 29th May, 1911 the second of three sons to wealthy Jewish parents. As a youth he was shy and retiring, but 
early it became clear that his gifts lay in the direction of science and mathematics. At high school George was greatly influenced by his teacher in mathematics and physics, K. (Charles) Novobátzky, who worked actively in the theory of relativity and was in 1945 to become a professor of theoretical physics at the University of Budapest. Small wonder that George's first great mathematical interest was relativity. The other major formative influence at high school was the journal 'Középiskolai Matematikai és Fizikai Lapok'. The names of problem solvers were published with each solution and with the completion of the year's volume, photographs of the main contributors were reproduced.

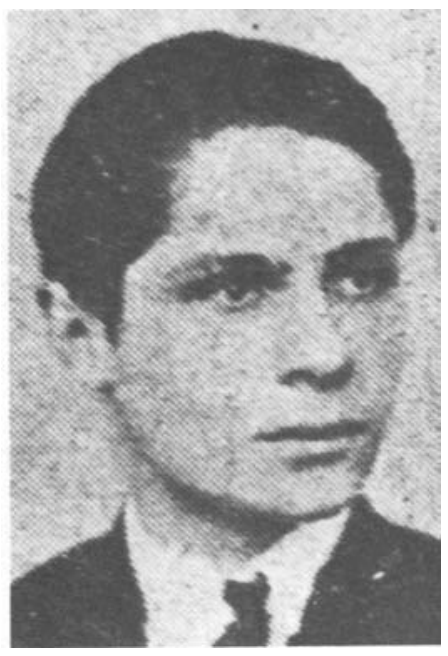

George Szekeres and Esther Klein as they appeared in the 1927-28 edition of the 'Lapok'.

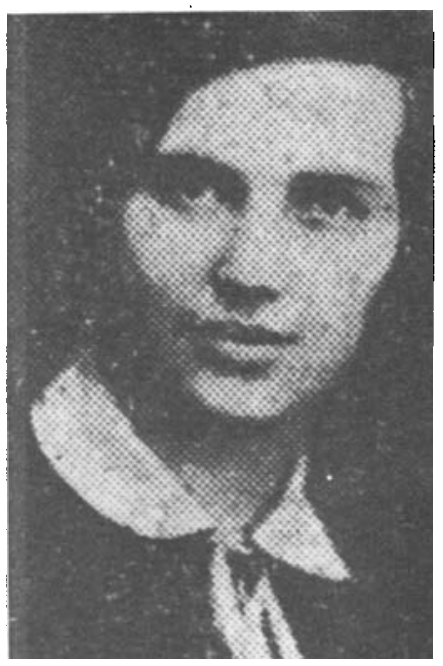

Each year the high schools were invited to send one student for each subject to take part in the high schools competition. George was entered by his school for physics (Esther also entered for physics). For Jewish students these competitions were of great importance as success ensured them one of the restricted university places.

So that he would be of service in his family's leather factory, George complied with his parents' wishes to study chemical engineering and he entered the Technological University in Budapest (Esther entered the Science University). However, from the problem solvers of the 'Lapok' now at the two university establishments in Budapest, a group of enthusiastic young mathematicians formed, organising weekly seminars at the City Park to pose problems and to discuss solutions. G. Pólya and G. Szegö's 'Aufgaben und Lehrsätze aus der Analysis' was religiously worked through in such sessions. The group included 
Paul Erdös and Paul Turán later to become highly respected figures in the mathematical world, and Esther Klein whom George was to marry. They often went on mathematical excursions, a favourite one being to swim to a small island in the Danube. H. Weyl's 'Raum, Zeit, Materie' made a great impression on George and it was on such excursions that he instructed his colleagues in Weyl's account of relativity.

While working for his diploma in chemical engineering the Szekeres family fortunes fell into decline and finally the business collapsed. These worries did not bother George but rather seemed to have the opposite effect; he became less retiring and he developed into a lively and stimulating personality. For a while he worked in a leather factory in Simontornya. During this time he continued his research in mathematics. His first great mathematical success was his rediscovery of Ramsey's theorem. Esther had proposed and solved a combinatorial problem in geometry and George and Paul Erdös set about generalising the result (1935). George's contribution was Ramsey's theorem on which the generalisation was seen to depend. Paul Erdös refers to this (Spencer (1973; p. 19)), as the 'Happy Ending Problem' because George and Esther married in 1937. A paper he wrote with Paul Turán on Hadamard matrices in this period bore fruit nearly thirty years later, after he had written a graph theory paper with Esther (1965), and his interest was largely responsible for work in this area by Australian mathematicians. The unavailability of advanced texts led to difficulties and disappointments in research. He did at this time make the exciting discovery of a marvellous matrix identity, only to learn that he had rediscovered the classical CayleyHamilton theorem.

For the period of their married life in Hungary, George and Esther were forced by economic necessity to live apart and meet only on weekends. As the events in Europe were becoming ominous for Jews, George and Esther fled to Shanghai, amazingly the only place available to them at that time. Their son Peter was born in Shanghai in 1940. George worked as a leather chemist when he could, but those were indescribably hard times. After the war he found clerical work in an American air force base, an occupation which left him with time on his hands for mathematics. It was during this time that he wrote his first group theory papers on abelian and metabelian groups (1948, 1949). In 1948 H. W. Sanders was instrumental in having George offered a lectureship at the University of Adelaide where he was to remain for the next fifteen years.

During his years at Adelaide, George worked in an astounding variety of fields. In number theory, his papers on partitions $(1951,1954)$ are perhaps the most significant. In algebra, a paper on ideals of a polynomial domain was the basis for a whole chapter in L. Redei's 'Algebra I' (1967). He published a number of papers in general relativity; sometimes significant achievements were 
published in a modest way. A paper on singularities of the Riemannian manifold (1960) anticipated by several years, intensive research which was to go into the problem of singularities in general relativity. In this paper he used his methods to derive an extension of the Schwarzschild solution, of interest in the class of peculiar phenomena known as "black holes". He was to begin major research on iteration of functions $(1958,1962)$, he continued with problems in combinatorics (1959), and with the coming of the computer age he made noteworthy contributions in numerical analysis $(1958,1962)$. In this period George was beginning to have a remarkable effect on the Australian mathematical community. George has always been an enthusiast and has always shown interest in others who have interesting research problems. He is encouraging with his students - the problem is the thing, the formal attainments of the person with the problem are of no relevance at all. Because of the width of his own research interests he was beginning to influence a growing number of young Australian mathematicians. In 1963 George was offered the Chair of Pure Mathematics at the University of New South Wales. He accepted the position only after assurances that the position would not require him to become an administrator. George, Esther, and daughter Judith, born in 1954, moved to Sydney in May 1963, while their son Peter was studying relativity in London for his $\mathrm{Ph} . \mathrm{D}$. At this time they were to learn that George had been elected a fellow of the Australian Academy of Science.

George is a convinced problem solver in his approach to mathematics; this is the legacy he carries from his early days in Hungary. On arriving in Sydney one of the first activities he became involved in was encouraging student mathematics journals and competitions of the type he had experienced in his youth. The high schools mathematics competition had begun in N.S.W. before George arrived there, but he soon became a major source of problems. The Sydney University Mathematics Society had instituted yearly problem competitions for undergraduate students; George has sustained that competition with a steady supply of problems. A high school journal 'Parabola' reminiscent of the 'Lapok' was instituted largely under his inspiration. George's casual conversation has over these years been concerned with a discussion of competition problems and their neat solutions. George was director of the fifth Summer Research Institute of the Australian Mathematical Society held in Canberra in January 1965; he brought overseas visitors such as Paul Erdös and Alfréd Rényi to Australia who were able to inspire activity amongst Australian mathematicians. George continued with his wide variety of mathematical interests and was extremely productive. In 1968 the Australian Academy of Science awarded him the Thomas Rankin Lyle Medal and the citation for that medal is a succinct summary of his work at that time. 
Professor G. Szekeres has published, in the period 1964-1968, thirteen research articles in a wide range of mathematical disciplines. Of particular significance are his papers giving the solution of a long outstanding problem on the fractional iterates of an entire function; a new practical method for computer evaluation of high dimensional integrals which eliminates some of the difficulties of the standard Monte Carlo methods; the solution of a problem in the theory of directed graphs which has pointed the way to new work in this field; and a new system of axioms for relativistic kinematics. These display a mastery of the concepts and techniques of analysis, algebra, numerical analysis, combinatorics and mathematical physics which is seldom found in one individual.

Since then he has published papers in number theory (1970) and numerical mathematics (1971) but his persistent field has been combinatorics and he remains obsessed with general relativity theory.

The Australian Mathematical Society, founded in 1956, had George as a foundation member. He served on the Council of the Society in the periods 1961-63 and 1971-75, and was President in the period 1972-74 and VicePresident in the periods 1971-72 and 1974-75.

George has supervised many postgraduate students and these are now scattered around the universities of Australia and overseas. His students in Adelaide included $\mathbf{J}$. H. Michael now reader at the University of Adelaide, I. N. Baker now reader at Imperial College London, C. F. Schubert now associate professor at Queens University, Ontario, Canada, T. W. Sag now senior lecturer at Flinders University, M. Sved now senior tutor at the University of Adelaide; (Marta, incidentally, was one of the group of mathematics students associated with George and Esther in Budapest). His students in Sydney included A. J. van der Poorten now senior lecturer at the University of N.S.W., J. M. Mack now senior lecturer at the University of Sydney, J. D. Gray now lecturer at the University of N.S.W., P. G. Trotter now lecturer at the University of Tasmania, R. F. Matlak now senior lecturer at Macquarie University, P. M. Diamond now lecturer at the University of Queensland, P. de C. Wark and J. Schutz now lecturers at Bendigo Institute of Technology, T. W. Atterton who died just after completing the work for his degree, J. S. Wallis now senior research fellow at the Australian National University and J. R. Giles now associate professor at the University of Newcastle. Students who have just graduated are Michael Cullinan and Bob Perry.

George and Esther live in a semi-bushland home in the Sydney suburb of Turramurra, among the sounds of the birds they love. George's spare time is 
taken up principally with music and especially chamber music; he is a keen violinist and he plays the viola for a local Sydney chamber orchestra. For exercise he enjoys hiking and camping, and for stimulation he enjoys conversation on a wide range of topic from art to politics.

\section{Publications}

'Über das zweite Hauptproblem der "Factorisatio Numerorum"' (with Turán, P.), Acta Szeged. 6 (1933), 143-154; (Zbl. 7,299).

'Über die Anzahl der Abelschen Gruppen gegebener Ordnung und über ein verwandtes zahlentheoretisches Problem' (with Erdös, P.), Acta Szeged. 7 (1934), 95-102; (Zbl. 10,294).

'A combinatorial problem in geometry' (with Erdös, P.), Compositio Math. 2 (1935), 463-470; (Zbl. 12,270).

'Note on lattice points within a parallelepiped', J. London Math. Soc. 12 (1937), 36-39; (Zbl. 15,391).

'On a problem of the lattice-plane', J. London Math. Soc. 12 (1937), 88-93; (Zb1. 16,368).

'Egy szélsöérték feladat a determinánselméletben' (with Turán, P.), Math. -nat. Anz. Ungar. Akad. Wiss. 56 (1937), 796-806; (Zbl. 18,387).

'Ein Problem über mehrere ebene Bereiche', Acta Szeged. 9 (1940), 247-252; (Zbl. 22,267).

'On an extremum problem in the plane', Amer. J. Math. 63 (1941), 208-210; (Zbl. 24,132).

'On a certain class of metabelian groups', Ann. of Math. (2) 49 (1948), 43-52; (MR 9,492).

'Countable Abelian groups without torsion', Duke Math. J. 15 (1948), 293-306; (MR 9,492).

'Determination of a certain family of finite metabelian groups', Trans. Amer. Math. Soc. 66 (1949), 1-43; (MR 11,320).

'The asymptotic behaviour of the coefficients of certain power series', Acta Szeged. 12 (1950), 187-198; (MR 13,220).

'New formulation of the general theory of relativity', Physical Rev. (2) 97 (1955), 212-223; (MR 16,869).

'A note on the volume of the unitary symmetrical space', J. Indian Math. Soc. (NS) 19 (1955), 127-132; (MR 18,121).

'On some exponential and polar representations of matrices' (with de Bruijn, N.G.), Nieuw Arch. Wisk. (3) 3 (1955), 20-32; (MR 16,785).

'On a property of monotone and convex functions', Proc. Amer. Math. Soc. 7 (1956), 351-353; (MR 18,23).

'An asymptotic formula in the theory of partitions', Quart. J. Math. Oxford (2) 2 (1951), 85-108; (MR 13,210).

'A canonical basis for the ideals of a polynomial domain', Amer. Math. Monthly 59 (1952), 379-386; (MR 13,903).

'Some asymptotic formulae in the theory of partitions (II)', Quart. J. Math. Oxford (2) 4 (1953), 96-111; (MR 15,201).

'Some asymptotic formulae in the theory of partitions' (with Roth, K.F.), Quart. J. Math. Oxford (2) 5 (1954), 241-259; (MR 16,797).

'Ether drift and gravitational motion', Phys. Rev. (2) 104 (1956), 1791-1798; (MR 18,703).

'Cosmic time and the field equations of general relativity', (with Kantor, W.), Phys. Rev. (2) 104 (1956), 831-834; (MR 19,103).

'On Borel fields over finite sets' (with Binet, F.E.), Ann. Math. Statist. 28 (1957), 494-498; (MR 19,1169).

'Spinor geometry and general field theory', J. Math. Mech. 6 (1957), 471-517; (MR 20\#747).

'On a problem of D. R. Hughes' (with Straus, E.G.), Proc. Amer. Math. Soc. 9 (1958), 157-158; (MR $20 \# 73)$.

' $(C, \infty)$ and $(H, \infty)$ methods of summation' (with Jakimovski, A.), Pacific J. Math. 8 (1958), 867-886;

(MR 21\#2133). 
'Regular iteration of real and complex functions', Acta Math. 100 (1958), 867-886; (MR 21\#5744).

'On the product $\Pi_{k=1}^{n}\left(1-Z^{a} k\right)$ ' (with Erdös, P.), Acad. Serbe Sci. Publ. Inst. Math. 13 (1959), 29-34; (MR 23\#A3721).

'Sur un problème de M. Paul Erdös' (with Schinzel, A.), Acta Szeged. 20 (1959), 221-229; (MR 22\#3710).

'Regular growth of real functions', Short Communs. Internat. Congress Math. pp. 67-68, (University Press, Cambridge, 1960).

'On the singularities of a Riemannian manifold', Publ. Math. Debrecen 7 (1960), 285-301; (MR 23\#A2842).

'On the propagation of gravitational waves', Magyar Tud. Akad. Mat. Kutató Int. Közl. 5 (1960), 3-15; (MR 23\#B2004).

'On finite metabelian p-groups with two generators', Acta Szeged. 21 (1960), 270-291; (MR 24\#A1941).

'On a theorem of Paul Lévy', Magyar Tud. Akad. Mat. Kutató Int. Közl. 5 (1960), 277-282; (MR 27\#1733).

'On some extremum problems in elementary geometry' (with Erdös, P.), Ann. Univ. Sci. Budapest. Eötvös Sect. Math. 3-4 (1960/61), 53-62; (MR 24 \# A3560).

'Fractional iteration of exponentially growing functions', J. Austral. Math. Soc 2 (1961/62), 301-320; (MR 25\# 5302).

'Tables of the logarithm of iteration of $e^{x}-1$ ' (with Morris, K.W.), J. Austral. Math. Soc. 2 (1961/62), 321-333; (MR 25\#5303).

'Fractional iteration of entire and rational functions', J. Austral. Math. Soc. 4 (1964), 129-142; (MR 29\#2368).

'Numerical evaluation of high-dimensional integrals' (with Sag, T.W.), Math. Comp. 18 (1964), 245-253; (MR 29\#2969).

'Some estimates of the coefficients in the Chebyshev series expansion of a function' (with Elliot, D.), Math. Comp. 19 (1965), 25-32; (MR 30\# 2666).

'On a problem of Schütte and Erdös' (with Szekeres, E.), Math. Gaz. 49 (1965), 290-293; (MR $32 \# 4025$ ).

'Behaviour of the Schwarzschild singularity in superimposed gravitational fields' (with Mysak, L.), Canad. J. Phys. 44 (1966), 617-627; (MR 32\#8986).

'On the approximation of real numbers by roots of integers', (with Mahler, K.), Acta Arith. 12 (1966/67), 315-320; (MR 35\#130).

'Metabelian groups with two generators', Proc. Internat. Conf. Theory of Groups pp. 323-346 (Gordon and Breach, New York, London, Paris, 1967); (MR 36\#5226).

'On the height of trees' (with Rényi, A.), J. Austral. Math. Soc. 7 (1967), 497-507; (MR 36\#2522).

'Analytic matrix functions' (with Gibson, J.K.), Nieuw Arch Wisk, (3) 15 (1967), 233-246; (MR $37 \# 1631$ ).

'An inequality for the chromatic number of a graph' (with Wilf, H. S.), J. Combinatorial Theory 4 (1968), 1-3; (MR 36\#1356).

'Kinematic geometry: an axiomatic system for Minkowski space-time', J. Austral. Math. Soc. 8 (1968), 134-160; (MR 37\#6098).

'A combinatorial interpretation of Ramanujan's continued fraction', Canad. Math. Bull. 11 (1968), 405-408; (MR 38\#1012).

'A new class of symmetric block designs', J. Combinatorial Theory 6 (1969), 219-221; (MR 38\#4334).

'Tournaments and Hadamard matrices', Enseignement Math. (2), 15 (1969), 269-278; (MR 40\#56).

'On a combinatorial generalization of 27 lines associated with a cubic surface' (with Ahrens, R.W.), J. Austral. Math. Soc. 10 (1969), 485-492; (MR 42\#4419).

'Ferde konfigurációk [Skew configurations.]', Mat. Lapok 20 (1969), 43-51; (MR 41\#3307).

'A skew Hadamard matrix of order 52' (with Blatt, D.), Canad. J. Math. 21 (1969), 1319-1322; (MR 40\#4140). 
'Multidimensional continued fractions', Ann. Univ. Sci. Budapest. Eötvös Sect. Math. 13 (1970), 113-140 (1971); (MR 47\#1753).

'Infinite iteration of integral summation methods', J. Analyse Math. 24 (1971), 1-51; (MR 44\#681).

'Cyclotomy and complementary difference sets', Acta Arith. 18 (1971), 349-353; (MR 45\# 209).

'The average value of skew Hadamard matrices', Proc. First Austral. Conf. Combinat. Math. pp. 55-59. (TUNRA, Newcastle, 1972); (Zbl. 267.05022).

'Polyhedral decompositions of cubic graphs', Bull. Austral. Math. Soc. 8 (1973), 367-387; (MR $48 \# 3785$ ).

'Determinants of skew type \pm 1 matrices', Period. Mat. Hungar. 3 (1973), 229-234; (Zbl. 267.05021).

'Oriented Tait graphs', J. Austral. Math. Soc. 16 (1973), 328-331; (Zbl. 269.05104).

'Polyhedral decomposition of trivalent graphs', Proc. Second Austral. Conf. Combinat. Math. pp. 125-127. (Lecture Notes in Mathematics, Springer No. 403, 1974).

'Non-colourable trivalent graphs' Proc. Third Austral. Conf. Combinat. Math. pp. 227-233. (Lecture Notes in Mathematics, Springer No. 452, 1975).

\section{Reference}

Joel Spencer (1973), 'The art of counting, selected writings of Paul Erdös', M.I.T. Press.

We would like to thank George's family and his many friends and colleagues who have contributed material for this article.

University of Newcastle

and

Institute of Advanced Studies, Australian National University, Canberra. 